\title{
Mendoza: vitivinicultura y transferencia de ingresos. Del sobrestock a la importación
}

\section{Martín Alejandro Ferreyra}

Universidad Nacional de Cuyo - CONICET.

Instituto Multidisciplinario de Estudios Sociales Contemporáneos,

Instituto de Estudios Históricos, Económicos, Sociales e Internacionales, Argentina

mferreyra@conicet.gov.ar

\section{Jorge Andrés Vera}

Centro de Estudios Ambientales de la NorPatagonia, Universidad Nacional de Río Negro. Centro de Estudios y Análisis Políticos, Universidad Nacional del Comahue, Argentina jvera@unrn.edu.ar

Cita sugerida: Ferreyra, M. A. y Vera, J. A. (2018). Mendoza: vitivinicultura y transferencia de ingresos. Del sobrestock a la importación. Mundo Agrario, 19(41), e087. https://doi.org/10.24215/15155994e087

Recibido: 22 de Noviembre 2017 - Aceptado: 14 de Mayo 2018 - Publicado: 15 de Agosto 2018

(c) (1) () Esta obra está bajo licencia Creative Commons Atribución-NoComercial-CompartirIgual 4.0 Internacional (c) 


\section{Mendoza: vitivinicultura y transferencia de ingresos. Del sobrestock a la importación}

Mendoza: vitiviniculture and income transfer. From overstock to import

Martin Alejandro Ferreyra

Instituto Multidisciplinario de Estudios Sociales Contemporáneos, Instituto de Estudios Históricos, Económicos, Sociales e Internacionales, Universidad Nacional de Cuyo. Consejo Nacional de Investigaciones Cientificasy Técnicas, Argentina, Argentina mferreyra@conicet.gov.ar

Jorge Andrés Vera

Centro de Estudios Ambientales de la NorPatagonia, Universidad Nacional de Río Negro. Centro de Estudios y Análisis Politicos, Universidad Nacional del Comahue, Argentina, Argentina jvera@unrn.edu.ar

\section{Resumen:}

Considerando que los mercados son construcciones sociales y, por lo tanto, los precios no son determinados \# exclusivamente\# por las fuerzas de la oferta y la demanda, el presente trabajo analiza el comportamiento económico de la industria vitivinícola mendocina en los últimos años, ponderando la capacidad de apropiación del excedente económico por parte de los agentes intervinientes del circuito productivo. En este marco, se parte de la hipótesis de que los agentes líderes construyen elementos ideológicos y dinámicos que les permiten configurar una relación asimétrica con respecto a los productores primarios

Palabras Clave: Circuitos productivos, Mendoza, Vitivinicultura, Productores primarios, Excedente económico.

\section{Abstract:}

Taking into consideration that markets are social constructions and, therefore, prices are not set \# exclusively\# by the forces of supply and demand, the present paper looks at the economic behavior of the winemaking industry at Mendoza during the last years, assessing the economic surplus appropriation capacity of the stakeholders involved in the productive circuit. Against this backdrop, the assumption is that leading stakeholders build dynamic and ideological elements that allow them to establish an asymmetrical relationship regarding primary producers

KEYWORDS: Productive circuits, Mendoza, Winemaking, Primary producers, Economic surplus.

\section{MENDOZA Y EL VINO}

La provincia de Mendoza presenta algunas particularidades en su funcionamiento económico. Si bien su producto bruto geográfico (PBG) no se vincula en forma exclusiva con la transformación de productos agropecuarios, la vitivinicultura representa culturalmente una actividad económica trascendental. Traducido en números: en los últimos veinte años, el PBG relacionado a la uva y a su elaboración en vino (considerando derivados) alcanza el 15\%, mientras que las actividades vinculadas con la extracción de petróleo y su refinación explican el 25\% (DEIE, 2017); asimismo, cabe destacar que la actividad petrolera genera alrededor de 5.000 puestos de trabajo en forma directa, mientras que la cadena productiva del vino - con sus actividades satélites e inducidas-supera los 100.000 empleos. De modo que la vitivinicultura debe dimensionarse por su capacidad de crear puestos de trabajo, a la par que cabe interpretar su bonanza o crisis, interpretarse como herramientas explicativas de las condiciones socioeconómicas de la región.

Si se analiza el escenario nacional, Mendoza aporta más del 75\% de la superficie plantada de vides del total del país; es sin dudas la principal provincia productora de vino, seguida por San Juan, con el 20\%. A la vez, Mendoza destina la totalidad de la uva a la vinificación, mientras que San Juan destina una parte de 
la uva producida a mercados alternativos, tal como el de la uva en fresco para mesa o el mercado de frutas desecadas. En la producción vitivinícola de la región cuyana conviven, además, diversas particularidades: innovaciones tecnológicas y comerciales, asociadas con el mercado externo; lo tradicional, exclusivamente dedicado al mercado internista y una vitivinicultura híbrida que no se ajusta de palmo a palmo ni con los modelos productivos fordistas ni con los posfordistas (Ferreyra y Vera, 2015).

\section{LAS POLÍTICAS MACRO Y LA EVOLUCIÓN DEL CIRCUITO}

El principal obstáculo histórico en materia de producción de vinos es el desequilibrio entre la oferta y demanda de uvas. Habitualmente se produce más de lo que se consume, de manera que se generan recurrentes crisis de sobrestock, lo que explicaría la caída de la rentabilidad de los diferentes actores del circuito. Este funcionamiento propio de la morfología del circuito vitivinícola se asume desde posicionamientos teóricos diferentes, que abarcan tanto argumentaciones ortodoxas/neoliberales (Day, 2013) como las más heterodoxas (Azpiazu y Basualdo, 2001). En este sentido, Day (2013) enfatiza que las políticas públicas orientadas a la compra de materias primas del vino (uvas y vino de traslado) generan la acumulación de stocks vínicos, lo que se traduce en una presión bajista de los precios. Azpiazu y Basualdo (2001) argumentan que la expansión de la superficie implantada con vides y los altos rendimientos de los nuevos viñedos, generan recurrentes crisis de oferta de excedente, con la consiguiente caída de precios.

A diferencia de otro tipo de producción agrícola, la vitivinicultura presenta características particulares en cuanto a su planificación. Una nueva unidad productiva no está en condiciones de entrar en funcionamiento pleno sino a partir de los cinco años de la plantación, lo que ocasiona dificultades en la adaptación de las producciones a las fluctuaciones del mercado. Para encontrar razones explicativas al fenómeno de sobrestock, se deben considerar diferentes factores. Al respecto, es preciso destacar los cambios que se han producido en el consumo de vino a nivel nacional y mundial. El vino ha pasado de ser una de las bebidas más populares en la mesa de los argentinos a convertirse en un producto de preferencias tendencialmente "sofisticadas" (en el Gráfico 1 se observa la caída del consumo de vino en la Argentina y en el resto de los países históricamente productores de vino). Es decir que la oferta del producto, estructurada históricamente, debe adaptarse a las nuevas pautas de consumo.

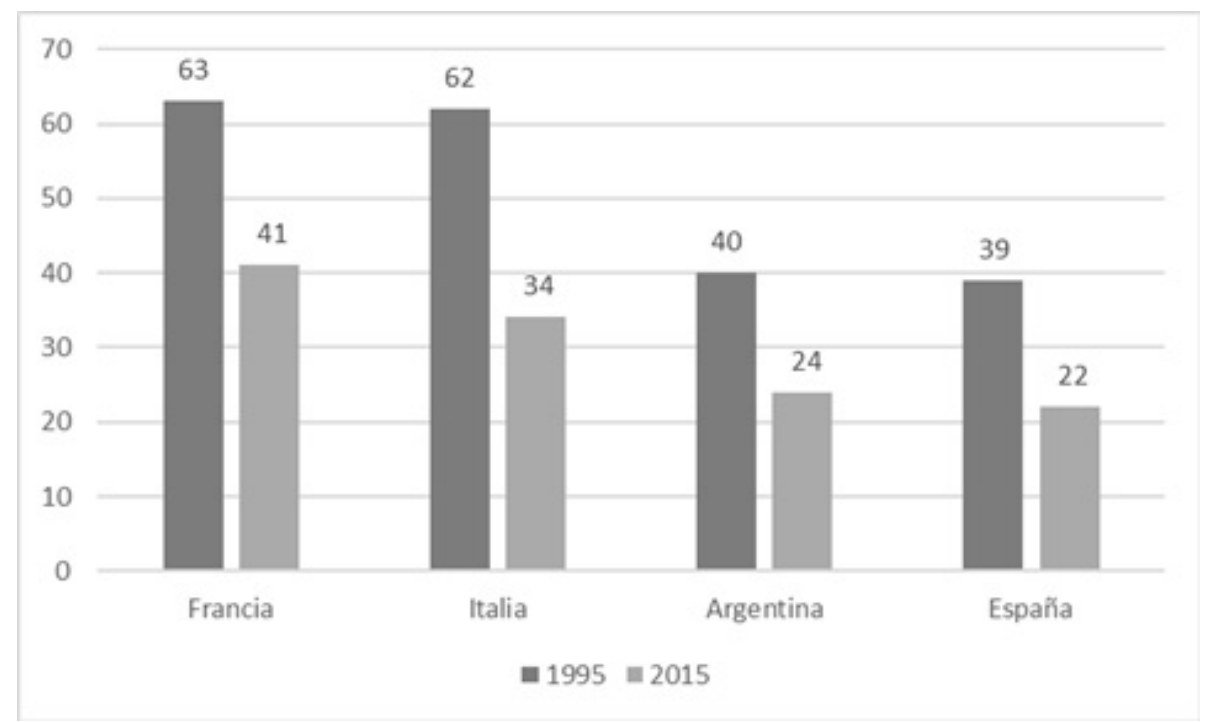

Gráfico 1 - Comparativo de consumo de vino de países productores (Litros per cápita). 1995-2015 Fuente: elaboración propia en base a The Wine Institute for California y Banco Mundial 
El nuevo escenario comercial de la vitivinicultura es otro factor a tener en cuenta. Cabe mencionar al respecto la aparición de un novedoso mercado externo, antes inexistente, y de un mercado interno diferente, vinculado con la producción de vino a partir de uvas finas; ambos mercados requieren formas de producción distintas de las tradicionales, las nuevas plantaciones de vid para mercados de mayores exigencias de calidad implican menor cantidad de kilos de uva producida por hectárea. La constante reconversión, es decir, pasar de trabajar con uvas de bajo valor enológico a otras de alto valor, favorece la disminución de la presión de la sobreoferta. Las uvas comunes (bajo valor enológico), cerezas y criollas, generan muchos kilos por hectárea (hasta 450 quintales), mientras que en el caso de uvas de alta calidad nunca se supera, en promedio, los 200 quintales. Las uvas de bajo valor enológico se destinan por lo general a "blancos escurridos": se trata del vino que sobra, es decir, que no encuentra demanda, según voceros de algunas cámaras. Por el contrario, el vino tinto falta. Entonces, la industria recurre a un proceso muy cuestionado pero frecuente: la utilización de uvas tintoreras para transformar vino blanco en tinto.

La utilización de la uva tintorera (aspirant bouchet) es controversial. Aunque genera rentabilidad para el productor primario, los vinos obtenidos con la utilización de estas uvas son de poca legitimidad. Según datos del Observatorio Vitivinícola Argentino, en el país existen 4.000 hectáreas de este cepaje; estas plantaciones crecieron exponencialmente en los últimos diez años alrededor del 200\%. Esta uva, sin ser de alto valor enológico, duplicó el valor de mercado de las uvas más demandadas, como por ejemplo el Malbec de Tupungato. La tendencia a una mayor superficie con plantación de esta uva, y su precio de mercado, demuestra que el circuito utiliza cada vez más la uva blanca para generar vino tinto, que es más requerido en el mercado y consigue mejores precios. Estos dos factores - la utilización de uvas criollas de bajo valor enológico y la irrupción de la uva tintorera- alteran la forma de producción de vino en la región. Es en este contexto que debe hablarse de un tipo de fraude en el sistema productivo por los agentes elaboradores. El exceso de uvas blancas paga muy por debajo del valor que adquiere el vino tinto común en las góndolas de los supermercados.

Es en este nuevo escenario que la industria en su conjunto implementó, ante el supuesto sobrestock vínico, una regulación específica que pretende ordenar los desequilibrios. El denominado acuerdo San JuanMendoza, vigente desde 1995, ordena destinar a los productores una parte importante de las cosechas a la generación de mosto, con el objetivo de dinamizar un mercado diferente al del vino. Esta medida implicó la generación de un mercado de mosto que inauguró una serie de conflictos entre distintos agentes. En principio, la normativa instrumenta límites al destino de uva a vino; su implementación determina, año a año -según los pronósticos de cosecha- qué porcentaje de la producción de uva deben destinar a la fabricación de mosto los agentes de las dos provincias. Estos porcentajes variaron, con máximos del $35 \%$ y mínimos del 10\%, según los pronósticos de cosechas. Pero no todos los productores cumplieron con la reglamentación y se creó una serie de excepciones que favorecieron a diferentes agentes, lo que evitaron vender uva más barata pagada a los industriales mosteros, generando disputas ya expresadas en otras oportunidades (Ferreyra, 2017).

$\mathrm{Al}$ analizar el año 2017 se evidencia que, de manera poco razonable, se estableció un porcentaje del 14\% para que los productores destinaran a mosto, pese a que la problemática de la escasez de vino ya era más que conocida por todos los actores del circuito y representantes del estado provincial. El correlato inevitable fue el incremento de las importaciones como consecuencia de las magras cosechas del bienio 16/17, cuando la producción no alcanzó a satisfacer la demanda total de vino.

\section{Consecuencia de este Proceso}

Al observar los despachos de vinos en la Argentina, se advierte una diferencia respecto del comportamiento en el resto del mundo. La relación porcentual es de 70/30 de tinto-blanco a nivel mundial, en tanto que en Argentina es de 85/15, respectivamente (OIV). Ahora bien, la superficie plantada de uva no satisface la cantidad de uva tinta despachada al mercado, ya que el $50 \%$ de la superficie implantada en nuestro país es de uva para el viejo modelo productivo/comercial, en el que los vinos blancos eran los más consumidos. 
En este escenario aparece la uva tintorera (aspirant bouchet), que se utiliza para obtener vino blanco y transformarlo en tinto. La función principal de esta uva es convertir vino blanco común, sin demanda, en vino tinto común. Con una proporción de un litro de vino proveniente de uvas tintoreras más nueve de vino blanco escurrido, se consiguen diez de vino tinto común 1.

Este producto rojo se cotiza el 30\% más que el vino blanco. La uva de bajo valor enológico (criolla, cereza, etcétera) se paga muy por debajo del precio que después adquiere en el mercado, ya transformada en vino tinto. Este proceso, desde luego, modifica las proporciones entre oferta-demanda y las formas de negociación que existen en el mercado; es decir, desaparece la escasez de tintas y continúa el exceso de blancas a la hora de la negociación de los precios entre los diferentes agentes económicos. En definitiva, se observa un desequilibrio en las negociaciones, que resulta de los bajos precios que se pagan a productores primarios, quienes participan cada vez menos en la apropiación de la renta total, mientras que el vino aumenta su precio en la góndola del supermercado. Este es uno de los dos procesos que conducen al trato desfavorable en la negociación para los viñateros atomizados del primer eslabón de la cadena.

A la vez, este proceso -que puede interpretarse como de asimetría de la información entre los agentes que componen la cadena- se complejiza a causa de otro factor: el régimen de competencia es muy poco competitivo. En este sentido, se observa un proceso de agudización de la tendencia hacia la concentración. Las tensiones, evidenciadas ya en la década de 1970, entre el primer y segundo eslabón continúan su tendencia inercial hacia la concentración y presentan -en los últimos años- una nueva disputa por la apropiación del excedente por parte del eslabón comercializador.

En la actualidad existen más de 17 mil productores primarios y muy pocos agentes industrializadores y comercializadores con posición fuerte en el mercado. Para ilustrar esta situación se puede indicar que solo tres agentes líderes llegan a satisfacer más del $90 \%$ del mercado interno de vinos comunes, apenas dos grandes compañías controlan más del 35\% de las ventas en el mercado exportador y solamente un puñado de seis compañías suman otra proporción igual. Es decir: menos de diez agentes dominan las exportaciones de vino en las que existen más de 600 jugadores (Ferreyra y Vera, 2015).

\section{EvOLUCIÓN DEL CONJUNTO DE LA INDUSTRIA EN EL NUEVO CONTEXTO ECONÓMICO}

Los primeros seis meses del 2017 muestran una caída en la comercialización total de vino en todos sus ítems. El promedio de la caída, según el INV (2017), fue del 5,5\%. Esta situación se agrava al considerar que el 2016 registró valores negativos y el conjunto del circuito cayó, según la misma fuente, el 13,2\%. La difícil situación de las economías regionales de los últimos años definitivamente se ha agudizado por el nuevo contexto político-económico vigente desde finales del 2015. Si bien el circuito productivo analizado tiende a acoplarse a las características de la economía agraria de la zona núcleo, buscando exportar -después de la década de 1990 - una parte significativa de su producción, la importancia relativa del mercado interno continúa siendo importante: más del $75 \%$ de lo producido se destina a satisfacer el consumo doméstico.

En este marco, la caída en el poder adquisitivo de los salarios del conjunto de la población y el aumento del precio final del vino produjeron una situación de vulnerabilidad para la producción, con la subsecuente generación de sobrestock. En el acumulado 2016/2017, el desplome del salario real se estima en torno al 7,3\%, expresado en términos de magnitudes reales. Este número representa 1,4 meses de salarios medios y dos meses jubilaciones mínimas (UNDAV, 2017); por su parte, el precio del vino tinto de traslado ha crecido en los dos últimos períodos un 145\%2 en dólares (gráfico 2), mientras que los costos de producción evidenciaron una suba del 26\% en dólares (COVIAR, 2017; INV, 2017). 


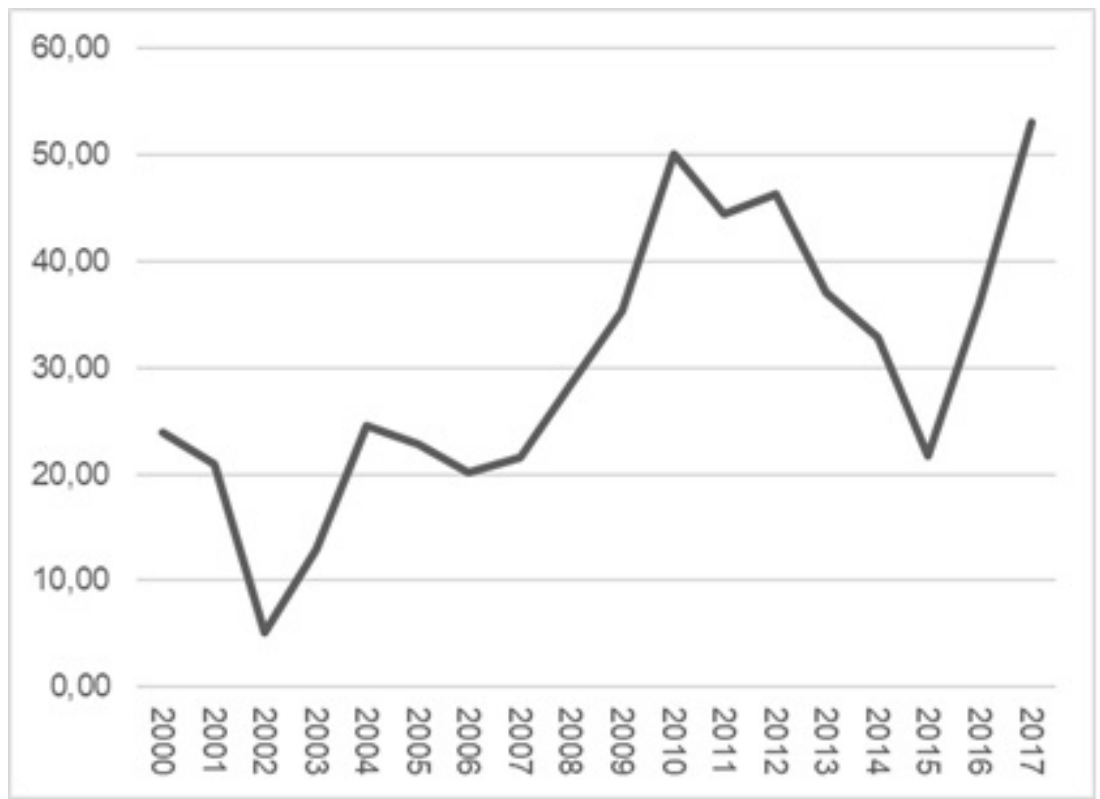

Gráfico 2 - Precio del vino tinto de traslado, en dólares x hl (2000-2017)

Fuente: Elaboración propia en base a INV y Asociación de Cooperativas Vitivinícolas Argentina (ACOVI).

El aumento de los costos productivos de las economías regionales explica la falta de competitividad en el mercado externo. La vitivinicultura no es la excepción. Aún más: las fincas que poseen riego de pozos, que demanda mucha energía eléctrica, quedaron prácticamente excluidas de poder funcionar luego de la quita de los subsidios y del aumento de la tarifa. Para ilustrar esta situación, según información del Instituto de Desarrollo Rural (IDR, 2016) y estimaciones publicadas por ACOVI (2017), el peso de la energía eléctrica consumida sobre los costos operativos totales, en un productor tipo, con un sistema de riego presurizado para 20 hectáreas, se incrementó entre noviembre de 2015 a diciembre de 2017 de un 3\% al 13\%. En este sentido, el Observatorio de ACOVI (2017), en su último informe sobre costos del año 2017, da cuenta del deterioro económico de los productores que utilizan pozo para riego, los cuales pierden anualmente $\$ 4.912$.

La estructura agrícola mendocina posee dos modalidades para el aprovechamiento del agua de riego. La primera, vinculada con la estructura tradicional, consta de un sistema de distribución del agua por una densa red de canales primarios o matrices, secundarios o ramas, terciarios o hijuelas y cuaternarios o ramos, que constituyó en su momento el sistema más eficiente y económico para el reparto del agua. Sin embargo, este sistema muestra algunas debilidades: por la inclinación de los terrenos, resultan privilegiados aquellos cuya pendiente favorece la circulación del agua, lo que redunda en una pugna entre los productores por la apropiación del recurso. Estos criterios para la apropiación del agua, junto con la red hídrica para la distribución, han perdurado por más de un siglo y todavía se mantienen en la mayor parte de la estructura agrícola mendocina (Jofré, 2011).

En los últimos años, el arribo de capitales productivos a la agricultura mendocina, como el capital tecnológico para riego de los predios, entre otros, generó una segunda modalidad. De modo que, en estos días, coexisten empresas agrícolas tradicionales con otras que han alcanzado una modernización integral de sus procesos productivos. Estas últimas empresas, en muchos casos provenientes del exterior, han transformado tanto el perfil tecnológico, social y económico del circuito vitivinícola mendocino, como las formas de regar los cultivos. La principal variable en este sentido es la radicación de sus fincas en zonas alejadas de los oasis tradicionales; la única forma de compensar este inconveniente, en un clima semidesértico, es la instalación de pozos para la extracción de aguas subterráneas. Asimismo, el bombeo de agua en relieves precordilleranos exige el cambio de las tradicionales técnicas de riego gravitacionales por técnicas presurizadas, más acordes a las nuevas exigencias de calidad de la producción agrícola. El riego presurizado, por goteo o aspersores, no solo 
ha permitido a las empresas innovadoras un uso más eficiente del agua, sino también un considerable ahorro de mano de obra, en la medida en que puede alcanzarse una automatización completa del sistema de riego, así como el aporte controlado de agroquímicos y la reducción en el crecimiento de malezas (Jofré, 2011).

Otro aspecto a considerar en la estructura de costos del circuito vitivinícola es el precio de los combustibles, que influye en dos cuestiones centrales de dicha la estructura: la mecanización de labores culturales y el flete que debe pagarse para transportar la uva a la bodega una vez cosechada. El precio del gasoil combustible creció alrededor del 65\% en un año y medio desde diciembre del 2015 (Ministerio de Energía y Minería, 2017). A la vez, la distancia entre la zona de producción y el puerto supone un costo de flete que duplica el costo del flete de exportación (ACOVI, 2017). Para complejizar este escenario, es importante destacar que los costos más significativos del eslabón industrial están dolarizados; las barricas de roble provienen principalmente de Estados Unidos o Francia, y el cartón y el vidrio, a pesar de su origen nacional, también se cotizan en moneda estadounidense.

En suma, se observa que el contexto actual imposibilita los dos posibles escenarios de valorización de los productos. Por un lado, no se estimula un proceso económico en el que la demanda potencial de los productos se pueda transformar en demanda efectiva y, por lo tanto, aumente el consumo per cápita nacional. Por otro, el vino se ha transformado en un producto relativamente caro con respecto a la competencia internacional y, en consecuencia, caen los volúmenes exportados. Debido a esto, la cadena experimenta una "tormenta perfecta": se estrangula tanto el mercado doméstico como el externo (ambos cayeron el 4,3\% en el primer semestre acumulado, comparado con igual período del año 2016). A la vez, en el mismo lapso, el mosto exportado también presenta una caída, según la misma fuente, del 46,7\%.

\begin{tabular}{|c|c|c|c|c|c|c|}
\hline \multirow{2}{*}{ Periodo } & \multicolumn{3}{|c|}{ Merc ado Intemo - Var. \% } & \multicolumn{3}{c|}{ Merc ado Extemo - Var. \% } \\
\cline { 2 - 7 } & Vino color & Vino blanco & Total & Vino color & Vino blanco & Total \\
\hline $07 / 2016$ y $07 / 2017$ & $-6,8$ & 3,5 & $-4,3$ & $-4,3$ & $-4,2$ & $-4,3$ \\
\hline
\end{tabular}

Cuadro 1 - Comercialización total de vino fraccionado. Comparativo 2016-2017

Fuente: elaboración propia en base a datos del Departamento de Estadísticas y Estudio de Mercado (INV, 2017)

\section{LA DINÁMICA DEL PRECIO DEL VINO}

Explicar el comportamiento de la industria que se tomó por caso para el presente artículo no es tarea sencilla, pues presenta diversos mercados de diferentes vinos. Para simplificar, servirá para ilustrar la situación actual una serie de precios promedio en dólares del vino tinto genérico de traslado, utilizados como precio proxy pagado a los productores primarios. Existen actualmente posiciones encontradas sobre los elementos que explican la determinación de los precios pagados al productor. La asociación de cooperativas vitivinícolas argumenta que:

El encarecimiento relativo del vino se explica por el significativo aumento del precio pagado al productor, proveniente de la escasez de la materia prima tras una magra cosecha, el incremento del costo de otros insumos vinculados al dólar, como el cartón para la caja, así como también por la suba de costos por la aceleración de la inflación y el encarecimiento de los servicios de luz y gas. (ACOVI, en Cavagnaro, 2017).

Posiciones en contra pueden encontrarse en representantes de otras cámaras, tales como el Centro de Viñateros y Bodegueros del Este. Mauro Sosa, gerente de esta asociación, se distancia de las explicaciones esgrimidas por ACOVI y ensaya otra interpretación:

El aumento en el precio del consumidor final es significativamente mayor que lo que le llega al productor. Entiendo que hay otros componentes vinculados con los insumos, pero tendrán que explicar cuáles son esos insumos para que el consumidor termine pagando más insumos que vino. Si nosotros tomamos la participación del productor en el mercado de traslado, esta no supera el 22\%. Esto no es lo que está generando distorsión en el consumo. Hay una gran diferencia entre lo que cuesta el vino escurrido y el precio final del consumidor. Hay una distorsión de la comercialización (Cavagnaro, 2017). 
En la misma línea, Gabriela Lizana, de la Asociación de Productores del Este Mendocino (APROEM) también disiente con el informe de ACOVI:

Esa es la excusa que siempre se tiene porque los productores son los más débiles de la cadena. Esto no es así. El porcentaje que ocupó el valor de la uva o del vino en el precio final desde hace cuatro años atrás sigue siendo el mismo. Un día el productor de uva o de vino va a regalar la uva o el vino va a seguir subiendo. Los que ganan son muchos actores que no es precisamente el sector productivo; apenas el sector ajustó los valores y ya parecemos los malos de la película. (Cavagnaro, 2017).

Diferentes precios relativos de los submercados implican diversas relaciones de fuerza entre agentes de distintos eslabones (Ferreyra, 2012). El precio del vino está relacionado, pero no exclusivamente, con el precio de la uva y con diferentes contingencias que pueden afectar la cantidad producida. La caída en la demanda tendría que tener consecuencias en el precio si este fuera un mercado que tendiera a explicarse por las leyes de la competencia perfecta. Pero como ya se ha advertido en trabajos anteriores, los mercados no suelen funcionar con estas lógicas. Desde el punto de vista del presente estudio, el precio del vino en los diferentes submercados constituye un indicador de la relación de fuerza de distintos agentes que participan en esta cadena. Para que esta relación de fuerza pueda permanecer en el tiempo, es necesaria una construcción ideológica que dé sustento a la asimétrica distribución de renta. La ley de la oferta y la demanda actúa en este sentido, ya que permite que se acepte la apropiación desigual del excedente económico entre los diferentes agentes que participan en el circuito. En cierta forma, estabiliza un modo de apropiación dentro de los límites compatibles con la cohesión social, ya que no son los agentes particulares los que constituyen una estructura desequilibrada de distribución, sino un ente arbitral que está por encima de los distintos competidores. Para dar cuenta de ello, se analizarán dos relaciones: la variación del precio en función de la oferta y la demanda, y la variación de los precios.

\section{EL SOBRESTOCK}

"En los últimos días, los medios han replicado el concepto de sobrestock de vino y lo han traducido en litros: 'Sobran 200 millones de litros en el mercado', enuncia un artículo de un portal de noticias de la UNCuyo de enero de 2016 (Unidiversidad, 2016). Si se tiene en cuenta el promedio demandado en los últimos dieciocho años, se observará que el nivel se sitúa en valores cercanos a los 17 millones de hectolitros (véase Anexo I).

A partir de las estadísticas relevadas por el INV (2017), se pueden determinar las temporadas que presentan un supuesto sobrestock de producción total -considerando las temporadas por encima de la línea promedio de demanda total, con valores cercanos a los 17 millones de hectolitros- y compararlas con el precio en dólares pagado en el mercado de traslado. La lógica de construcción de precios ortodoxa (traccionada por las cantidades ofertadas y demandadas) no parece del todo correcta para el caso estudiado. Si se siguiera ese criterio debería producirse el siguiente escenario: a mayor sobrestock, menor precio.

Sin embargo, el Gráfico 3 permite establecer fuertes cuestionamientos a esta argumentación. A la vez, si se analiza el período 2002-2008 también quedará desestimado el análisis ortodoxo, pues se observa una tendencia positiva general de precios (estables entre el 2004 y el 2007) conjuntamente con sucesivos y marcados sobrestocks. 


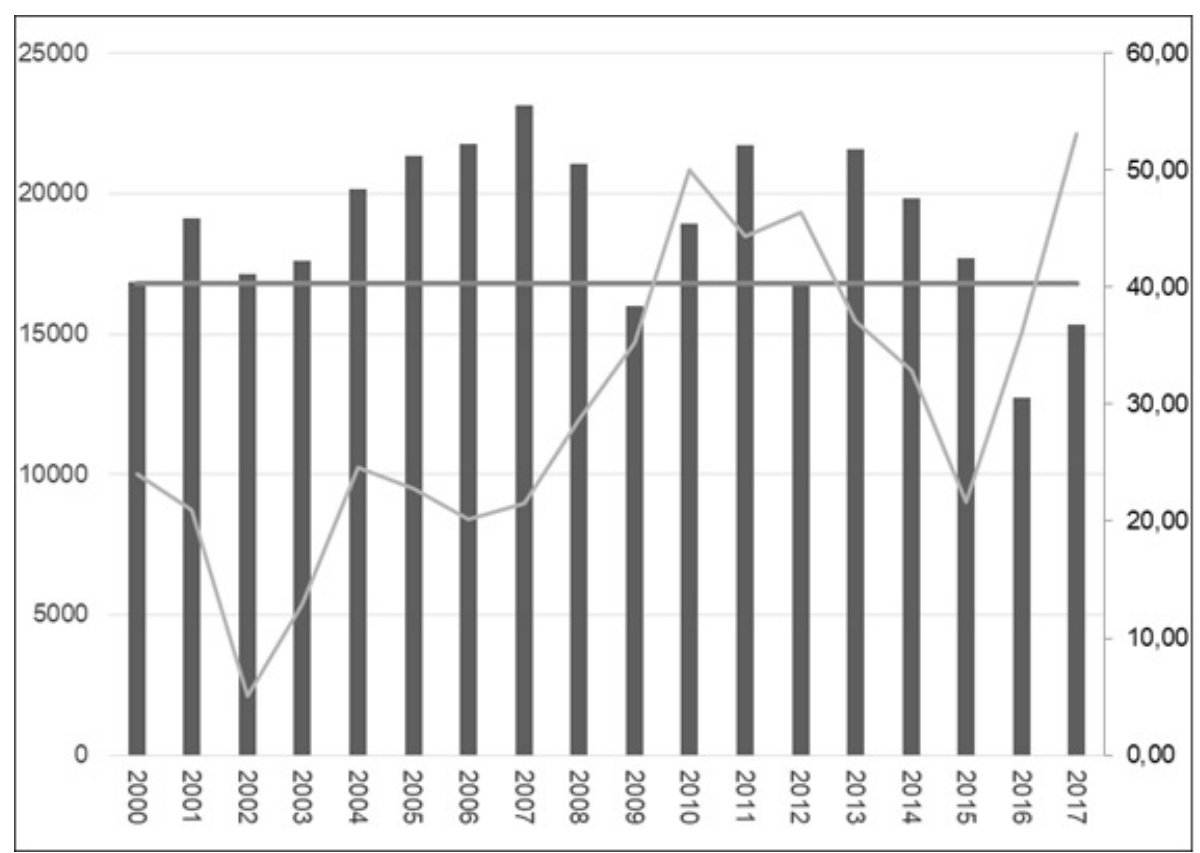

Gráfico 3 - Stock de vino en miles de hl y línea promedio de demanda total (eje principal)

- Precio del vino tinto de traslado, en dólares x hl (eje secundario). Años 2000-2017

Fuente: elaboración propia en base al INV y la Asociación de Cooperativas

Vitivinícolas Argentina (ACOVI) La importación. De la abundancia a la escasez

\section{LA iMPORTACión. De LA ABUNDANCIA A LA ESCASEZ}

"Desde hace un tiempo, la Argentina importa desde Chile la bebida nacional de los argentinos. A esta problemática se le suma la denuncia por parte de productores chilenos y locales, quienes aseguraron que el vino importado está siendo adulterado".

(Scariot, Núñez y Rodríguez, 2017)

La importación de vinos puede analizarse desde diferentes puntos de vista. Resulta curioso que el mismo medio de comunicación que en enero de 2016 vinculaba la problemática con el sobrestock de vino, en la actualidad observa un escenario totalmente diferente.

Si se observa con detenimiento el Gráfico 4, se verá que el acumulado del 2017 presenta un incremento de las importaciones de una magnitud superior a toda la serie. A diferencia de otros años de importación de vinos, como por ejemplo el 2010, este fenómeno se produjo en una fase expansiva de los mercados.

Argentina es uno de los grandes productores y consumidores de vino del mundo, se encuentra entre los diez primeros en ambos registros (OIV). Desde los años noventa, la vitivinicultura encuentra en los mercados de ultramar un nuevo destino a sus productos y muestra una tendencia extrovertida, es decir, exporta una parte significativa de la producción de vinos. Además, a diferencia de los restantes países de América, tiene un importante mercado interno, que históricamente se satisface con producción local. Sin embargo, en el 2017 se observa un comportamiento diferente a los patrones históricos. En este sentido, las importaciones de volúmenes significativos abastecen y modifican los precios relativos en algunos submercados. 


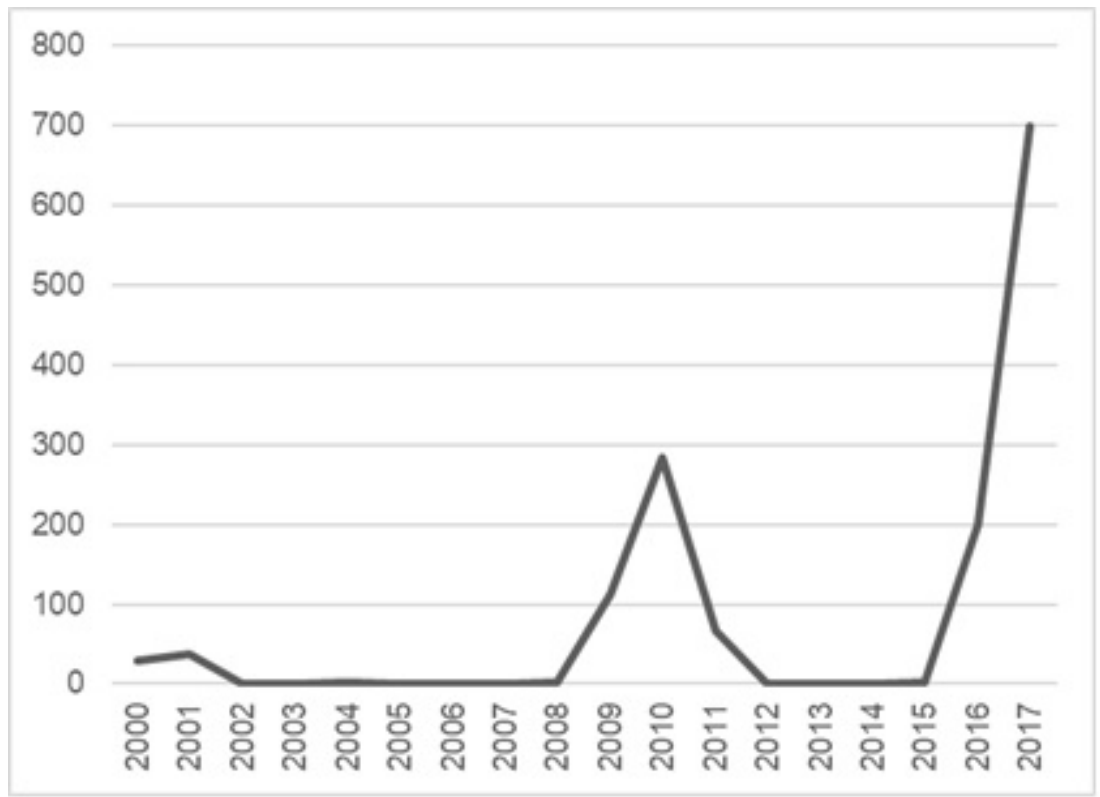

Gráfico 4 - Importaciones de vino en miles de hl. Años 2000-2017

Fuente: elaboración propia en base a INV y Asociación de Cooperativas Vitivinícolas Argentina (ACOVI)

Las últimas dos cosechas (2016 y 2017), por debajo del promedio histórico, habrían cambiado la tendencia de supuestos sobrestocks, dejando el camino abierto a la apertura de importaciones para satisfacer la demanda interna. Así, se pasó de volúmenes importados de menos de 3,3 millones -en los dieciséis años previos-a más de 70 millones de litros en el año en curso (INV, 2017). De modo que el constante sobrestock que justificaba la presión hacia la baja sobre los precios de la uva y el vino no era lo suficientemente fuerte como para sostener un par de cosechas. Por otro lado, ante una recuperación del precio de la uva, es evidente la utilización de las importaciones para regular su precio a la baja. En ambas situaciones los productores primarios son los perjudicados; el desempeño económico de estas variables no se acepta en términos generales por los agentes intervinientes en la producción. Los productores de la provincia de San Juan y los del Este mendocino han comenzado a mostrar su descontento y a manifestarse críticamente ante el funcionamiento del mercado. En este sentido, genera controversia y descontento con el ingreso de vino chileno, dado que en Chile está permitido el agregado exógeno de agua en el proceso productivo.

Según la presidenta de APROEM, los grupos que conforman el oligopsonio, tales como Peñaflor, Fecovita y Baggio, que manejan el $80 \%$ de la comercialización de los vinos tetrabrick y conforman más del 50\% de la producción de vinos, buscan un producto barato afuera del país; los perjudicados son el productor y el consumidor. Aunque el productor suba su producto un peso, eso luego repercute en la góndola en seis o siete pesos. Es decir que, aunque igual regalemos el producto, este seguirá subiendo en la góndola, porque no se revisa la cadena comercial, en la que hay desmedidas ganancias de algunos en detrimento del sector productivo. (Lizzana, 2017).

Como se afirmó en párrafos precedentes, lo contradictorio de este proceso es que se produce en un contexto de crisis de los mercados en cuanto a volúmenes y precios comercializados. Existen dos posiciones ante este fenómeno. La primera, vinculada a representantes de industriales y a comercializadores, justifica el ingreso de importaciones para poder mantener compromisos, controlar costos y evitar el ingreso de productos terminados europeos. Esto se puede observar en las declaraciones del gerente de la Unión Vitivinícola Argentina (UVA), Sergio Villanueva, quien manifestó que las cosechas del 2015 y del 2016 fueron las más bajas de los últimos 57 años, a causa de una serie de factores, desde climáticos hasta agronómicos: "Había dos opciones, o no abastecíamos la demanda y dejábamos que supermercados importaran botellas italianas o españolas, o traíamos vino chileno a granel" (Basile, 2017). 
La segunda posición está relacionada con los productores primarios y los industriales sin capacidad de fraccionamiento, quienes advierten acerca de los perjuicios de la importación y alertan por la competencia desleal. Mencionan dos circunstancias: por un lado, que el vino importado es un producto diferente al producido regionalmente, dado que el vino chileno contiene hasta el $7 \%$ de agua; por otro, que este proceso es parte de una estrategia de los fraccionadores para bajar el precio del vino de traslado y, por ende, de la uva de los productores primarios. El descontento se materializó en iniciativas judiciales por parte de los productores cuyanos. Las acciones para frenar la importación de caldos chilenos están pronto a llegar a la Justicia federal, ya que las cámaras vitivinícolas de San Juan y de Mendoza presentarán un amparo para prohibir el arribo de vino a granel. En contraposición, los representantes de los agentes importadores ven de mala forma esta medida: "El amparo es absurdo, porque Chile es un exportador de vinos a granel y hay acuerdos comerciales. Tiene que ver con los vaivenes de la industria. Si mañana Chile tiene una mala cosecha, la situación podría ser inversa". "No se puede poner condiciones para importar y pedir libertades para exportar". "Pueden presentar un amparo, pero no llegará a ningún lado porque el mundo moderno va en otra dirección, más cuando se compra vino extranjero por una necesidad puntual", afirma al respecto el dirigente de UVA.

La controversia no solo tiene que ver con comprar vino chileno y las consecuencias negativas que traería aparejado para la industria y las zonas donde están emplazadas las plantaciones, sino también con lo que algunos productores llaman "competencia desleal". Chile regula las características técnicas de lo que se considera vino diferente a la Argentina. Desde el 2015 su legislación permite agregar el 7\% de agua exógena al vino. El acuerdo firmado con Chile y otros países se produjo en el 2004, ratificado por ley nacional. Pero en ese momento el marco general para entender el acuerdo se basaba en las normas de la Organización Internacional del Vino (OIV), y esa normativa afirma que el agregado de agua anula la posibilidad de tipificar como vino a la producción. Chile, al modificar unilateralmente la regulación, incumple los acuerdos pactados anteriormente (Lizzana, 2017). El hecho de no poder efectuar una equiparación de los productos generó una competencia desleal. La ley de vinos argentina es clara en el sentido de prohibir la incorporación de agua exógena a la elaboración de vinos. Incluso el vino en estas condiciones debe ser inmovilizado y derramado. Asimismo, los encargados técnicos (enólogos) que incurren en estas prácticas, consideradas faltas muy graves, son sancionados. Pero la importación y comercialización del vino procedencia de Chile no incurriría en dichas faltas, porque el producto que se está trayendo no es vino para la ley argentina.

Para sintetizar, desde fines del 2015 a fines del primer semestre del 2017 -es decir, el primer año y medio del gobierno de la alianza PRO-UCR Cambiemos, bajo la presidencia de Mauricio Macri-, se importó el $70 \%$ más de vino que el total importado en los dieciséis años previos. En buena parte, podría decirse que en el mercado nacional se está vendiendo, actualmente, vino con agua. El silencio de la Corporación Vitivinícola Argentina (COVIAR), organismo encargado de planificar y promocionar la industria, puede ser interpretado como signo de complicidad con los agentes concentrados del circuito.

\section{CARACTERÍSTICAS DE LA IMPORTACIÓN}

Si bien hay importación de vino de todas partes del mundo, los únicos valores significativos son los vinos a granel importados de Chile. Se puede deducir que los vinos importados son aquellos que afectan a los agentes menos integrados de la cadena y los más vulnerables. El total de lo importado de Chile tiene que ver con vinos para el mercado doméstico común, es por ello que los más críticos a esta situación son los representantes de las zonas productivas donde menos se ha reconvertido la actividad, tal es el caso de los productores del Este mendocino y de San Juan. En este sentido, tenemos que advertir que el Este mendocino aporta más del 30\% de la uva que se cosecha del país, producción que supera lo generado por toda la provincia de San Juan, que produce el $20 \%$ de la uva del país. Esto explica que los agentes emplazados en esta zona sean los más perjudicados. El fenómeno vinculado a la importación no puede explicarse como la consecuencia de la autorregulación del mercado, sino que es resultado de una política deliberada que privilegia negocios del 
sector más concentrado de la actividad, "sin que esto suene a queja chauvinista hueca, sino a manifestación de incapacidad no solo de un sector de la economía sino de la dinámica de un país” (Saharrea, 2017).

El Estado -nacional y provincial- ha cedido definitivamente la regulación y el control de las relaciones entre los distintos agentes económicos al "mercado". Esto implica en la práctica el fortalecimiento de los agentes concentrados, permitiéndoles incidir en los precios y, con ello, limitar las condiciones socioeconómicas de los más de 10.000 productores primarios atomizados afincados en la provincia de Mendoza. Por otra parte, no se observa que con las importaciones bajen los precios, como podría esperarse. Tanto los vinos blancos como los vinos tintos tienen en la actualidad un precio más elevado en el mercado minorista respecto del 2016, el 90\% más los primeros, y el 160\% más los segundos (ACOVI, 2017), incrementos muy por encima de los índices de inflación.

Este proceso redunda en la necesidad de algunos agentes de mantener una posición privilegiada a la hora de negociar los precios. Se trata de una forma que encuentran los agentes concentrados para deteriorar el poder de negociación de los agentes primarios, ya que esta variable no funciona en este caso para bajar o estabilizar los precios en góndola del vino.

\section{LA RENTA}

La renta del circuito es el resultado del precio final en el mercado minorista del vino ponderado multiplicado por la cantidad de litros conseguidos. En la masa de vinos comercializados existen varios segmentos: puede observarse un segmento de vinos que promedian los 450 pesos y otro de vinos que promedian los 50 pesos por litro en góndola; entre esos dos extremos, hay una serie de segmentos con una alta variación de precios. Sin dudas, los cambios en los precios relativos traccionan cambios en las preferencias de consumo. En el 2015 se vislumbraba un escenario comercial3 en el que el precio ponderado del vino era de 45 por litro en góndola de supermercado (Ferreyra y Vera, 2015); si se replican los mismos pasos, el precio del vino ponderado en la actualidad ronda los 166 pesos por litro.

En el 2015, la renta fue de 4.330 millones de dólares; hoy es de 8.789 millones de dólares. Si se toma la diferencia entre precio final y precio ponderado, puede observarse que el productor pierde capacidad de retención de parte del precio final: pasa de una diferencia de 16 veces en el 2015, a 17,6 en el 2017. Al detenerse en el análisis de esta renta en el submercado de vinos más barato, se observa el comportamiento que ilustra el Gráfico 5. A pesar del ingreso de las importaciones vínicas significativas, el precio evolucionó significativamente hacia el alza.

Por el contrario, los precios en el mercado final aumentan en forma considerable si se compara con el precio de vino de traslado, que es la referencia (precio proxy) que se utiliza para pagar la uva a los productores primarios.

Los productores primarios presentan una tenue recuperación de sus márgenes de ganancia a pesar de las magras cosechas que se han conseguido en los dos últimos años, que tendrían que haber presionado el precio al alza de la uva. Esta mejora del $145 \%$ en dos temporadas en el precio de vino de traslado, se percibe sensiblemente menor al aumento del precio ponderado al consumidor, el cual aumenta el 170\%, incrementando la brecha entre precios pagados a productores y precio de góndola (Gráfico 5). Este aumento de la brecha implica el incremento de la diferencia de apropiación de renta entre diferentes agentes del circuito. 


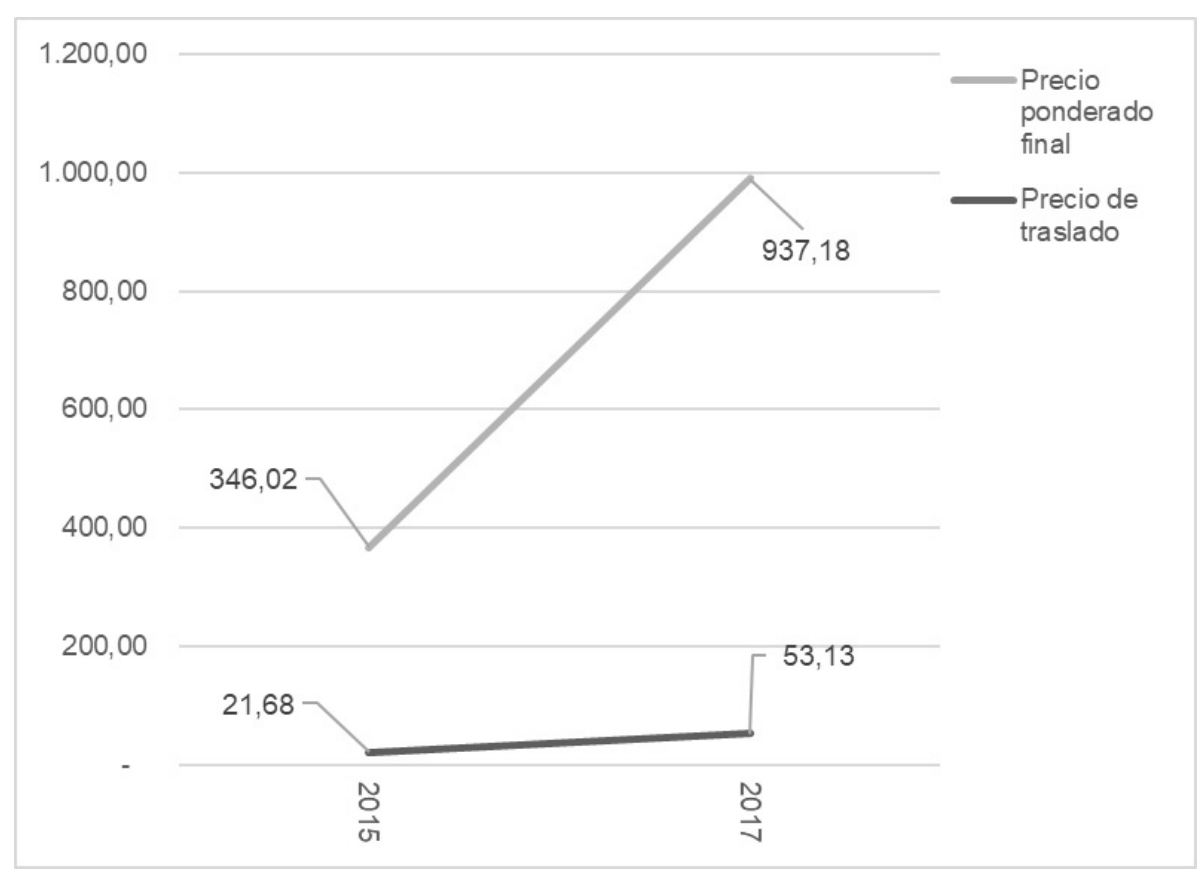

Gráfico 5 - Precio del vino traslado y precio ponderado al consumidor (en U\$S). Años 2015-2017 Fuente: Elaboración propia en base a INV y Asociación de Cooperativas Vitivinícolas Argentina (ACOVI)

El Gráfico 6 permite observar con claridad el dinamismo de la renta: las bonanzas y las crisis no son distribuidas de la misma forma entre los agentes que conforman una cadena de valor. En la comparación de las dos rentas, además, mientras más valor agregado tiene el vino, más se agranda la diferencia entre productores y comercializadores. Una de las cuestiones subyacentes es que los líderes del circuito son aquellos que venden los insumos en seco; el negocio no está en producir vino, sino en vender botellas y cajas. De modo que podría inducirse que los agentes más grandes no solo son productores de vino sino también comerciantes del packaging que se le incorpora. El eslabón industrial concentrado de la industria vitivinícola es el constante ganador en esta cadena.

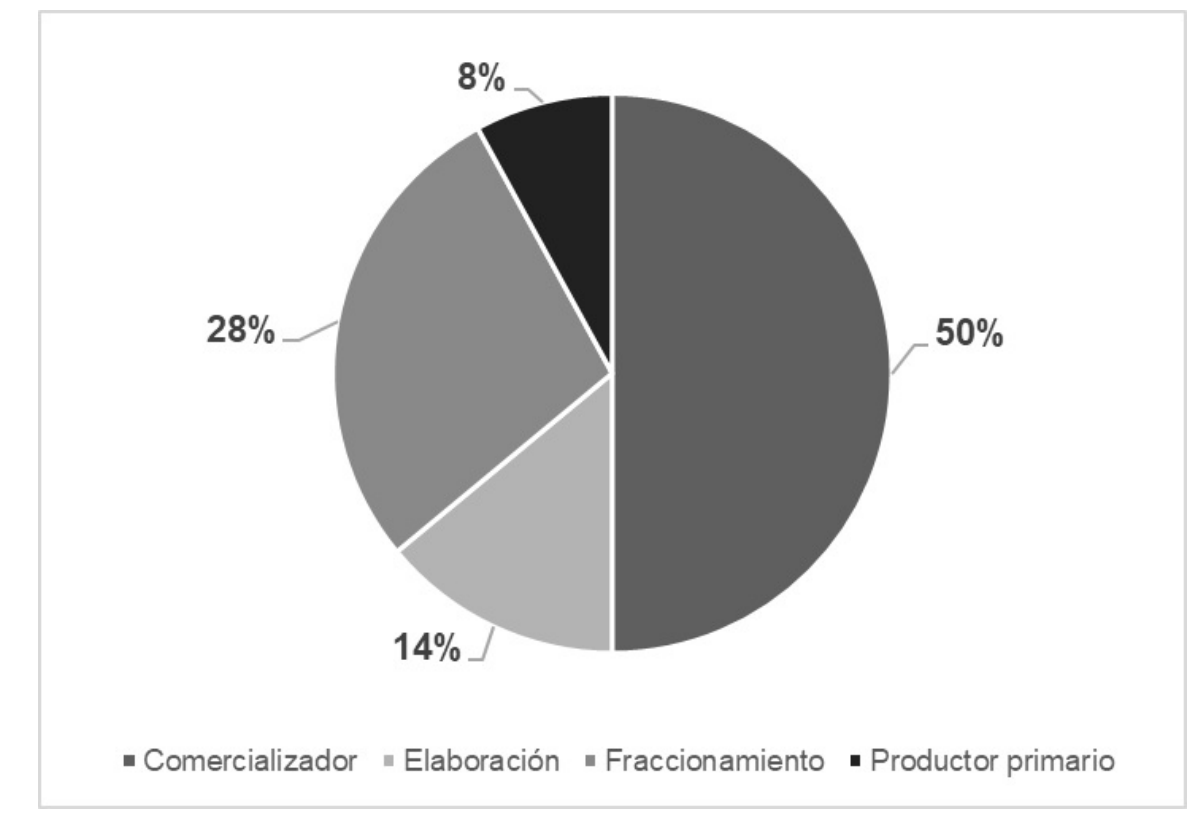

Gráfico 6 - Distribución de la renta por distintos eslabonamientos. Vino tinto Tetrabrick. Año 2017 fuente: elaboración propia en base a datos de acovi 


\section{Consideraciones FinALES}

La industria vitivinícola asocia sus dificultades a la falta de adecuación que existe entre la oferta de los productores y la demanda de los mercados. Esto, sin embargo, no constituye el principal indicador de las complicaciones que imposibilitan los márgenes de rentabilidad necesarios, para que la vitivinicultura se transforme en una actividad sustentable desde los planos económico, social y ecológico. El mercado analizado estructura un escaso criterio de transparencia en cuanto a la generación de valor y apropiación de los excedentes generados. En este sentido, se observa que las uvas de bajo valor enológico, inicialmente, no poseen precios de mercado, aunque después - por procesos de transformación en vinos tintos-adquieren un precio más elevado; este último valor no se les reconoce a los productores primarios, generando inequidad en el reparto de la renta. Por otro lado, hay un excedente de uvas criollas y un faltante de tintas; un teñido de las primeras implica una forma de transferencia de renta de los eslabones primarios a los agentes con capacidad de transformación.

$\mathrm{Al}$ analizar detenidamente la oferta y la demanda, se observa que este juego consolida una matriz simbólica utilizada por agentes con mayor poder de negociación a la hora de determinar el precio. Cuando existe una sobreoferta, el precio tiende a bajar; pero cuando la oferta es escasa, el precio no sube con la misma tendencia. Los agentes demandantes, en condición oligopsónica, aprovechan algunos elementos ideológicos para justificar el comportamiento del precio de la uva. Es decir, la causalidad argumentada desde las empresas dominantes se refiere en determinadas situaciones al sobrestock y en otras a la importación, impactando en variaciones del precio, que tienden a favorecer -siempre- a dichas empresas. Las figuras del sobrestock y de la importación son elementos que se valen para configurar un poder de negociación desigual, con el objetivo de pujar por los precios. Con la fuerte importación, el negocio del vino agudiza -en los dos últimos añosla tendencia a privilegiar la rentabilidad de la comercialización más que de la producción. Por lo tanto, los agentes concentrados no solo son parte de la producción, sino que también obtienen ganancias superlativas a partir de la comercialización. Es decir que -a la luz de lo desarrollado en este trabajo- el negocio en el circuito productivo vitivinícola actual no es producir sino comercializar.

Para finalizar, advertimos que el nuevo escenario político económico de Argentina pone en una situación de inviabilidad al circuito productivo analizado. Por un lado, se afecta la dinámica interna ya que aumenta el precio del vino en el mercado doméstico y baja el poder adquisitivo de la población; por otro lado, aumentan los costos de producción por la alta inflación, lo que transforma en poco competitivos a los productos vínicos nacionales con respecto a la competencia internacional. La política vigente no genera posibles escenarios de valorización de los productos; es decir, que no se estimula un proceso económico, vinculado al desarrollo del mercado interno, en el que la demanda potencial de los productos se pueda transformar en demanda efectiva y, por tanto, aumentar el consumo per cápita en Argentina (deprimido en los últimos 25 años), ni tampoco se orientan estrategias tendientes a reducir los costos de producción y logística, con el objetivo de ser más competitivos a nivel internacional. 


\section{ANEXO I}

\begin{tabular}{|c|c|c|c|c|}
\hline Año & $\begin{array}{c}\text { Demanda de } \\
\text { vino HL }\end{array}$ & $\begin{array}{l}\text { Consumo } \\
\text { interno HL }\end{array}$ & $\begin{array}{c}\text { Exportaciones } \\
\text { HL }\end{array}$ & $\begin{array}{c}\text { Otros } \\
\text { productos } \\
\text { vínicos }\end{array}$ \\
\hline 2000 & 15.240 .696 & 12.491 .263 & 843.023 & 1.906 .410 \\
\hline 2001 & 15.200 .639 & 12.036 .444 & 881.618 & 2.282 .577 \\
\hline 2002 & 16.326 .708 & 11.988 .496 & 1.234 .409 & 3.103 .803 \\
\hline 2003 & 17.715 .175 & 12.338 .416 & 1.852 .260 & 3.524 .499 \\
\hline 2004 & 16.107 .931 & 11.112 .578 & 1.553 .391 & 3.441 .962 \\
\hline 2005 & 17.625 .468 & 10.972 .454 & 2.147 .759 & 4.505 .255 \\
\hline 2006 & 19.351 .418 & 11.103 .938 & 2.934 .248 & 5.313 .232 \\
\hline 2007 & 21.292 .123 & 11.165 .998 & 3.597 .702 & 6.528 .423 \\
\hline 2008 & 21.144 .763 & 10.677 .191 & 4.140 .548 & 6.327 .024 \\
\hline 2009 & 16.662 .448 & 10.342 .267 & 2.830 .491 & 3.489 .690 \\
\hline 2010 & 15.504 .788 & 9.753 .081 & 2.744 .311 & 3.007 .396 \\
\hline 2011 & 17.733 .554 & 9.795 .667 & 3.115 .417 & 4.822 .470 \\
\hline 2012 & 18.530 .983 & 10.050 .928 & 3.656 .429 & 4.823 .626 \\
\hline 2013 & 17.691 .188 & 10.351 .751 & 3.150 .515 & 4.188 .922 \\
\hline 2014 & 16.436 .027 & 9.913 .213 & 2.625 .613 & 3.897 .201 \\
\hline 2015 & 16.923 .162 & 10.210 .609 & 2.756 .894 & 3.955 .659 \\
\hline 2016 & 12.014 .713 & 9.416 .300 & 2.598 .413 & - \\
\hline 2017 & 11.353 .904 & 8.898 .404 & 2.343 .768 & 111.732 \\
\hline
\end{tabular}

Fuente: elaboración propia en base a datos de INV. (2017 datos provisorios)

\section{Fuentes}

ACOVI (2017). Informes vitivinícolas. Disponibles en: http://acovi.com.ar/observatorio/category/inform es-periodicos/

Basile, A. (2017). Productores, a la Justicia para frenar importación de vinos. Ámbito financiero. Disponible en http://www.ambito.com/894593-productores-a-la-justicia-para-frenar-importacion-de-vinos.

Bustos Herreras, M. (2017). Importaciones de vino de Chile. Estrategias y Mercados. Disponible en http: //estrategiasymercados.com/index.php/2017/01/26/importaciones-de-vino-de-chile/

Cavagnaro, M. (2017). Vamos a regalar la uva y el vino va a seguir subiendo. Diario MDZon line. Recuperado de https://www.mdzol.com/nota/755804-vamos-a-regalar-la-uva-y-el-vino-va-a-seguir-subien do/

DEIE (2017). Producto Bruto Geográfico. Disponible en http://www.deie.mendoza.gov.ar/\#!/articulo/ producto-bruto-geografico-51

González, M. S. (2015). En 40 años el consumo per cápita de vino bajó 70\%. Diario Los Andes. Disponible en http://www.losandes.com.ar/article/print/articulo/en-40-anos-el-consumo-per-capita-de-vino-bajo-70

IDR (2016). Publicaciones económicas. Disponible en http://www.idr.org.ar/economicas/

INV (2017). Informes anuales de vinos y mostos. Disponible en http://www.inv.gov.ar/index.php/info rmes-anuales 
Lizzana, G. (2017). Competimos con vino de Chile rebajado con agua. Diario Bichos de Campo. Disponible en http://bichosdecampo.com/gabriela-liziana-competimos-vino-chile-rebajado-agua/

Saharrea, S. (2017). El vino, bien argentino como Arturo Vidal”. Tiempo de San Juan. Disponible en http ://www.tiempodesanjuan.com/politica/2017/8/26/vino-bien-argentino-como-arturo-vidal-188246.html

Saig, L. (2017). Aspirant bouchet, la vedette del año. Diario Los Andes. Disponible en: http://www.losa ndes.com.ar/article/aspirant-bouchet-la-vedette-del-ano

Scariot, N., Nuñez, G. y Rodríguez, L. (2017). Queja por la importación: 'La calidad del vino está asegurada'. Disponible en http://www.unidiversidad.com.ar/importacion-de-vinos-la-calidad-del-vino-arge ntino-esta-asegurada-la-del-chileno-no

UNDAV (2017). Inflación y salarios. Disponible en: http://eppa.com.ar/6352-2/

Unidiversidad (2016). ¿Por qué sobran 200 millones de litros de vino?. Unidiversidad. Recuperado de ht tp://www.unidiversidad.com.ar/crisis-vitivinicola-local-por-que-sobran-200-millones-de-litros-de-vino

\section{SITIOS WEB DE INTERÉS}

ACOVI (Asociación de Cooperativas Vitivinícolas Argentinas) http://www.acovi.com.ar

DEIE (Dirección de Estadísticas e Investigaciones Económicas ) http://www.deie.mendoza.gov.ar (Error 3: El enlace externo www.deie.mendoza.gov.ar debe ser una url) (Error 4: La url www.deie.mendoza.gov.ar no esta bien escrita)

INV (Instituto Nacional de Vitivinicultura) http://www.inv.gov.ar

Ministerio de Energía y Minería de la Nación http://www.argentina.gob.ar/energiaymineria

OVA (Observatorio Vitivinícola Argentino) http://www.observatoriova.com (Error 9: El enlace externo www.observatoriova.com debe ser una url) (Error 10: La url www.observatoriova.com no esta bien escrita)

OIV (Organización Internacional de la Viña y el Vino) http://www.oiv.in

\section{ENTREVISTAS}

Cristóbal Sola (productor primario / empresario proveedor de plantas)

Gabriela Lizzana (presidenta de APROEN)

\section{REFERENCIAS}

Abihaggle, C., Aciar, A. y Luque, L. (2015). Distribución de la renta vitivinicola: Análisis y propuestas para mejorar y estabilizar la participación del sector primario. Disponible en http://www.uncuyo.edu.ar/relacionesinternacion ales/upload/informe-final.pdf

Azpiazu, D. y Basualdo, E. (2001). El complejo vitivinicola argentino en los noventa: potencialidades y restricciones. Buenos Aires: FLACSO. Disponible en http://bibliotecavirtual.clacso.org.ar/ar/libros/argentina/flacso/no11 \%20_ComplejoVitivinicolaArgentino_20.pdf

Day, J. (2013). Una Argentina competitiva, productiva y federal. Actualidad y desafios en la cadena vitivinicola de Argentina, 19(124). 22 de noviembre de 2013. IERAL- Fundación Mediterránea. Disponible en http://www.ie ral.org/images_db/noticias_archivos/2697-Plan\%20Federal\%20-\%20Vitivin\%C3\%ADcola\%202013.pdf

Ferreyra, M. (2017). Vitivinicultura en tensión: El caso de la regulación pública en Mendoza (Argentina). En A. García (comp.), Territorio y politicas públicas en el Sur. Dinámicas socioeconómicas en Argentina y Brasil a principios de siglo XXI. Buenos Aires: Biblos. 
Ferreyra, M. y Vera, J. A. (2015). La evolución de la industria del vino en la provincia de Mendoza y la fruta fresca de pepita en Río Negro y Neuquén, en tiempos de post-convertibilidad. 2003-2014. Ponencia en la Primera Reunión Tendencias y Debates en Historia Económica Argentina "Expansión de la frontera productiva y estructura agropecuaria”. CEHIR-ISHIR-CONICET, co-organizado -AAHE- y las FHyEyA de la UNComa. Neuquén.

Ferreyra, M. (2012). El cambio en los valores relativos de los precios en la cadena de valor del vino argentino. Revista Eletrônica da Associação dos Geógrafos Brasileiros (AGB) - Seção Três Lagoas. Disponible en http://www.cptl.uf ms.br/geo/revista-geo/Revista/Revista16/1.pdf

Fiochetta, C. y Rada, D. (coordinadores) (2016). La vitivinicultura argentina en el mundo: equilibrio, crecimiento y desarrollo. Disponible en http://observatoriova.com/wp-content/uploads/2017/05/Jornadas-Estratégicas-deCOVIAR-2016-La-vitivinicultura-argentina-en-el-mundo-Equilibro-Crecimiento-Desarrollo.pdf

Jofré, J. L. (2011). Efectos de las innovaciones productivas en la agricultura sobre la materialidad institucional del régimen hídrico. El caso mendocino entre 1976-2010 (Tesis doctoral). Buenos Aires: FLACSO, sin publicar.

\section{Notas}

1 Información brindada por el especialista Ing. Cristóbal Sola.

2 Los precios del vino de traslado pagados por hectolitro en la temporada 2015 fue de U\$S21,68, y en la temporada 2017 ascendió a U\$S53,13 (http://acovi.com.ar/observatorio/series-estadisticas-5/)

3 Para poder calcular el precio de un litro de vino en el mercado doméstico nos apoyaremos en un trabajo de la consultora Kantar realizado para el Observatorio Vitivinícola de la Bolsa de Comercio de Mendoza. Las encuestas realizadas entre enero y abril del año 2015 a 4.000 hogares de todo el país dicen que el 54\% de los hogares argentinos consume vino. El consumo se distribuye de la siguiente manera: los vinos más baratos envasados en tetrabrik alcanzan al 34\% de los comercializados; los vinos denominados finitos llegan al $21 \%$ del mercado; los que se catalogan como medio bajo representan un $12 \%$ de ventas; los que se denominan medio llegan al 6\%; y, por último, los vinos reserva y Premium, que tienen un $27 \%$ del mercado. A partir de estos porcentajes seleccionamos los mismos vinos de cada segmento y construimos un precio ponderado estimado del vino en un agente comercializador (Mayorista Macro) de vino a octubre de 2015 . 